\title{
COMPARATIVE THERMAL RELATIONSHIPS OF FLIGHT FOR SOME BATS IN THE SOUTHWESTERN UNITED STATES
}

\author{
Michael J. O'Farrell and W. Glen Bradley \\ Zoological Society of Nevada, P.O. Box 4036 Las Vegas, NV 89106, U.S.A. and Department of \\ Biological Sciences, University of Nevada, Las Vegas, NV 89154, U.S.A.
}

(Received 9 November 1976)

\begin{abstract}
Nine of eleven species of desert bats tested demonstrated the ability to initiate and maintain flight at reduced body temperatures. This ability is associated with periodic activity throughout the winter.

2. Of the two species studied most intensively, Pipistrellus hesperus demonstrated a stronger relationship between ambient and body temperatures than did $M$ yotis californicus. It is hypothesized that differences in total body insulation are responsible for the difference in this relationship.

3. Pipistrellus hesperus shows seasonal shifts in actual flight body temperature with a difference of $8-10^{\circ} \mathrm{C}$ between summer and winter. Spring and fall represent transition periods where the body temperature responds more directly to ambient temperature. Myotis californicus shows the same patterns only to a lesser extent.

4. Low temperature flight appears to be an inherent physiological mechanism with no significant differences observed during laboratory experiments on a sexual or seasonal basis.

5. Some variability is observed which appears to reflect the body condition and caloric and water balance.

6. It is proposed that low temperature flight associated with winter activity is a mechanism adaptive for maintenance of water balance; but only incidentally of value as $\boldsymbol{a}$ feeding strategy.
\end{abstract}

\section{INTRODUCTION}

Intensive studies have been conducted concerning thermoregulation of bats (for references see Henshaw, 1970; Lyman, 1970; Studier \& O'Farrell, 1972). Most, however, have dealt with laboratory responses of nonflying bats over a wide range of temperatures which may or may not have related to the animals' natural thermal exposure. Most studies have suggested that active bats behave as homeotherms, maintaining high, relatively constant body temperatures and that resting bats tend towards facultative poikilothermy, wherein body temperatures approximate ambient temperatures.

Flight at reduced body temperature was first shown for bats by Bradley \& O'Farrell (1969) and further documented by Studier \& O'Farrell (1972). This physiological phenomenon appears to be associated with bats that are active throughout the year (O'Farrell \& Bradley, 1970) or with hibernators which exhibit some intra- and inter-roost winter movements (Henshaw \& Folk, 1966). Such a capability is obviously of importance in reducing energy expenditures for flight under environmental stress.

This study presents field data on body temperatures of flying bats over a wide range of environmental temperatures and deals with the direct relationship between body temperature and ambient temperature. The phenomenon of low body temperature flight is further supported by determination of minimal body temperatures for flight under laboratory conditions. The widespread nature of low body temperature flight and the unique ecological relationships involved are discussed. Most studies on thermoregulation in bats have assumed that all flying bats are homeothermic. Interpretations of experimental data from the literature need, therefore, to be reevaluated in the light of capability of low body temperature flight in many bats.

\section{MATERIALS AND METHODS}

\section{Field measurements}

The following bats were collected throughout southern Nevada from 600 to $2700 \mathrm{~m}$ elevation: Pipistrellus hesperus, $M$ yotis californicus, $M$. volans, $M$. evotis, Eptesicus fuscus, Lasiurus cinereus, Antrozous pallidus and Tadarida brasiliensis. All body temperatures $\left(T_{b}\right)$ were taken rectally from bats mist-netted over water as described by O'Farrell \& Bradley $(1970)$. Ambient temperature $\left(T_{a}\right)$ and $T_{b}$ were recorded within $1 \mathrm{~min}$ of capture with the use of a Schultheiss quick-registering mercury thermometer. Body temperatures obtained this rapidly after capture should not differ significantly from true flight temperatures (Bradley \& O'Farrell, 1969).

\section{Laboratory measurements}

Most bats used in laboratory experiments were obtained by mist-netting, except for several Plecotus townsendii and $M$. californicus which were taken from hibernacula. In the laboratory flight trials were conducted using the method of Bradley \& O'Farrell (1969). After being cooled, bats were allowed to warm passively with minimal disturbance. At $T_{b}$ greater than $15^{\circ} \mathrm{C}$, and at approximately $1{ }^{\circ} \mathrm{C}$ intervals thereafter each individual was tossed over a net and flight behavior noted. Our criteria for good flight entailed maintenance or gain in altitude across the room, usually 
Table 1. Regression analysis of the $T_{b} T_{a}$ relationship for field-caught bats. Sexes and seasons are combined

\begin{tabular}{|c|c|c|c|c|c|}
\hline Species & $N$ & Equation & $r^{2}$ & $T_{b}$ rangc & $T_{a}$ range \\
\hline Myotis erotis & 49 & $\begin{array}{c}T_{h}=21.56+0.75 T_{a} \\
(0.11)\end{array}$ & 0.51 & $24.5-37.4$ & $6.0 \quad 23.3$ \\
\hline Myotis volans & 41 & $\begin{array}{c}T_{b}=\frac{23.02+0.65}{(0.08)} \\
T_{a}\end{array}$ & 0.64 & $25.0-38.3$ & $x(1)-22.2$ \\
\hline Myotis californicus & 82 & $\begin{array}{c}T_{b}=28.80+0.33 T_{a} \\
(0.03)\end{array}$ & 0.61 & $25.0-38.4$ & $-5.0 \ldots 28.3$ \\
\hline Pipistrellus hesperus & 287 & $\begin{array}{c}T_{b}=24.56 \quad \mid \quad 0.46 T_{a} \\
(0.0 !)\end{array}$ & 0.81 & 21.838 .8 & $5.0 \quad 30.0$ \\
\hline Eptesicus fuscus & $2 x$ & $\begin{array}{c}T_{b}=\frac{28.97+0.33}{(0.05)} \\
T_{a}\end{array}$ & 0.64 & 28.741 .0 & 4.534 .5 \\
\hline Lasiurus cinercus & 31 & $\begin{array}{c}T_{b}=29.93+0.34 T_{a} \\
(0.04)\end{array}$ & 0.73 & $31.0-40.2$ & $5.0-29.4$ \\
\hline Antrozous pallidus & 50 & $\begin{array}{c}T_{b}=30.04+0.24 T_{a} \\
(0.04)\end{array}$ & 0.49 & $28.7-40.6$ & $5.6-35.2$ \\
\hline Tadarida brasiliensis & 19 & $\begin{array}{c}T_{h}=29.04+0.30 T_{a} \\
(0.04)\end{array}$ & 0.65 & $31.1-38.0$ & $12.0-35.0$ \\
\hline
\end{tabular}

accompanied by aerial maneuvers. Usually a series of flight trials were obtained on each individual tested.

\section{RESLLTS}

\section{Field body temperature determinations}

Eight species of bats were collected at various times of the year over a wide range of $T_{a}$. Three species, $P$. hesperts, $M$. californicus and $A$. pallidus, were netted in all seasons; the others were absent from winter collections. Only $P$. hesperus and $M$. californicus represented numerous captures at low $T_{a}$ inasmuch as $A$ pallidus was uncommon at all collection sites.

The relationship between $T_{b}$ and $T_{a}\left(T_{b}-T_{a}\right)$ for all species is shown in Table 1. Flight $T_{b}$ was directly related to $T_{a}$ in all species. Although no significant differences in thermal response were found between sexes the amplitude of $T_{b}$ response to $T_{a}$ varied greatly among the species. Three species, $P$. hesperus, $M$. volans and $M$. evotis, exhibit a more pronounced response of $T_{b} T_{a}$ than the remaining species (Table 1). Predictability should be increased for most species when sufficient $T_{b}$ data are collected at low $T_{a}$.

Sufficient numbers of $P$. hesperus and $M$. californicus were captured throughout the year to allow a more detailed analysis. A strong direct relationship between flight $T_{b}$ and $T_{a}$ is apparent for both species throughout the year (Fig. 1). The slopes were significantly different between species $(P<0.01)$ indicating that the magnitude of $T_{b}$ response to $T_{a}$ is greater in $P$. hesperus than in $M$. californicus (Fig. 1). This may be a reflection of differences in insulation.

An examination of seasonal responses of $T_{b}-T_{a}$ for both species clarified the differences in annual $T_{b}-T_{a}$ response (Fig. 2). The data presented in Figs 1 and 2 are identical. but subdivided by season. So few $M$. califomicus were obtained in the spring and fall that these data were combined. The slopes for both species are all significantly different from zero except for winter $M$. californicus. The seasonal differences for $M$. californicus were not significant. $P$. hesperus, however, shows no significant differences between certain seasons (Table 2). It is evident that for this species, flight $T_{b}$ is not as responsive to $T_{a}$ fluctuations in summer and winter as in spring and fall.

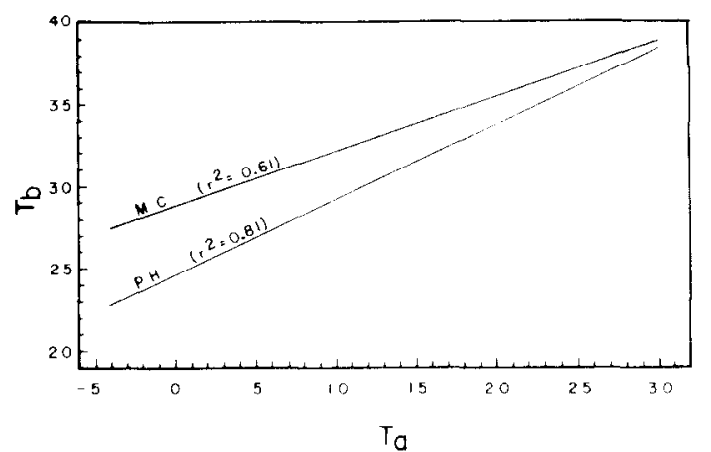

Fig. 1. The antual response of body temperature $\left(T_{h}\right)$ to ambient temperature $\left(T_{a}\right)$ for flying bats in southern Nevada. $\mathrm{MC}=$ Myotis californicus and $\mathrm{PH}=$ Pipistrellus hesperus

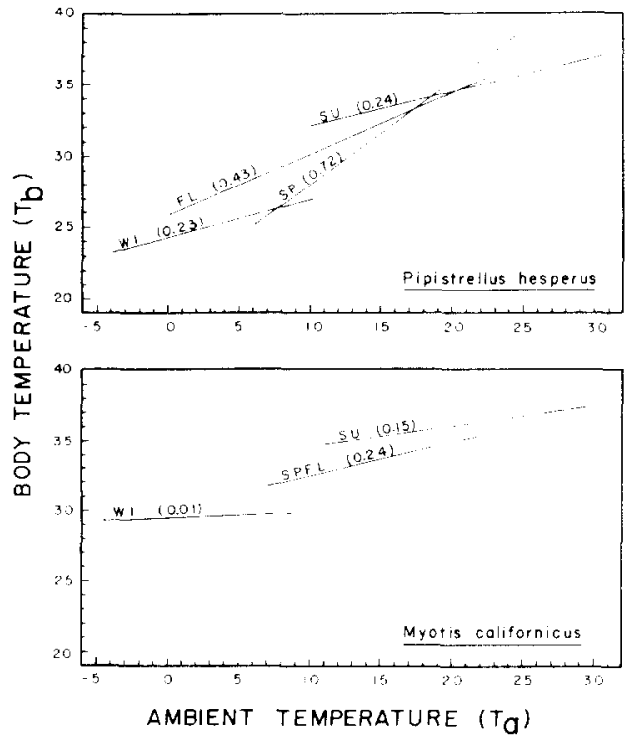

Fig. 2. The response of body temperature $\left(T_{b}\right)$ to ambient temperature $\left(T_{a}\right)$ by season for flying bats in southern Nevada. $\quad \mathrm{SP}=$ spring; $\quad \mathrm{SU}=$ summer $\quad \mathrm{FL}=$ fall ; $\mathrm{WI}=$ winter. Slopes are given in parentheses. 
Table 2. Regression analysis of the $T_{b}-T_{\mathrm{a}}$ relationship for Pipistrellus hesperus by season

\begin{tabular}{lccc}
\hline Season & $N$ & Equation $^{*}$ & $r^{2}$ \\
\hline Spring & 21 & $T_{b}=\begin{array}{c}20.81+0.72 T_{a}^{\mathrm{c}} \\
(0.12)\end{array}$ & 0.66 \\
Summer & 165 & $T_{b}=\begin{array}{c}29.67+0.24 T_{a}^{\mathrm{a}} \\
(0.03)\end{array}$ & 0.32 \\
Fall & 57 & $T_{b}=\begin{array}{c}25.85+0.43 T_{a}^{b, \mathrm{c}} \\
(0.04)\end{array}$ & 0.67 \\
Winter & 44 & $T_{b}=\begin{array}{c}24.43+0.23 T_{a}^{\mathrm{a}, \mathrm{h}} \\
(0.09)\end{array}$ & 0.15 \\
\hline
\end{tabular}

* Matched superscripts indicate no significant difference in slopes.

\section{Laboratory flight trials}

The documentation of low flight $T_{b}$ under field conditions makes it desirable to determine the lowest $T_{b}$ at which these bats can achieve flight. A summary of mean minimum $T_{b}$ for flight is given by Studier \& O'Farrell (1972). More complete data for some southwestern bats are given in Table 3 . Nine of the eleven species were capable of flight at mean $T_{b}$ less than $28^{\circ} \mathrm{C}$; however, each species exhibited high variability. Where possible, minimum $T_{b}$ for flight was analyzed by sex and season, although no significant differences were found. Evidently, if a species is capable of low $T_{b}$ flight it will function in this manner regardless of sex or seasonal acclimatization.

To illustrate the variability in minimum $T_{h}$ for flight, flight trials for a single $P$. townsendii is shown in Fig. 3. This individual was captured on 3 November from a local hibernaculum, taken to the laboratory and returned to hibernation in an environmental chamber. Flight trials were conducted over a span of 8 days during which no food or water was provided. It is apparent that with an increase in stress (food and water deprivation), the bat was able to fly at progressively lower $T_{b}$, as low as $19.6^{\circ} \mathrm{C}$. The erratic pattern of the third set of flight trials was probably due to approaching terminal stress. Similar results were obtained from two other $P$. townsendii (both sexes) tested at the same time.

\section{DISCUSSION}

A positive correlation between $T_{b}$ and $T_{a}$ in active, flying $P$. hesperus has been documented and described in detail (Bradley \& O'Farrell, 1969). Further information on this species as well as $\boldsymbol{M}$. californicus have been collected and comparatively analyzed. Daily activity patterns for both species are quite similar with the majority of activity occurring during the early hours of the evening. On a seasonal basis they differ, with a higher percentage of $M$. californicus being captured during the winter (O'Farrell \& Bradley, 1970).

An annual summary of thermoregulation during flight for both species (Fig. 1) demonstrates a significant difference. Although both species are low $T_{b}$ fliers, it is apparent that $P$. hesperus responds more strongly to $T_{a}$ than $M$. californicus, and $P$. hesperus can fly at lower $T_{b}$. Scholander et al. (1950) listed three main avenues for adaptation to cold: (1) $T_{b}-T_{a}$ gradient, (2) insulation, and (3) basal metabolic rate. As they pointed out, heat loss was proportional to the $T_{b}-T_{a}$ gradient; animals conserve heat by maintaining a lower $T_{b}$. This would place $P$. hesperus in a more advantageous position with its ability to maintain a significantly lower $T_{b}-T_{a}$ differential. At present, we have no quantitative measures of insulation for either species, but a gross examination reveals that $P$. hesperus is sparsely furred whereas $M$. californicus is woolly. Both species are within the same weight range (2.5-5.5 g) with $M$. californicus averaging slightly larger. At present we have no reason to believe that metabolic rates, at comparable $T_{b}$ particularly in flight, are significantly different. Therefore, we propose that differences in conductance may account for the significantly higher $T_{b}-T_{a}$ response of $M$. californicus.

The seasonal examination of $T_{b}$ response (Fig. 2) raises several interesting points. The slopes of the winter and summer $T_{b}-T_{a}$ responses are identical with no significant statistical relationship to $T_{a}$. During fall and spring, however, there is a strong positive $T_{b}-T_{a}$ relationship in $P$. hesperus. It should be stressed that although a statistical relationship was not found in some seasons that a direct, positive $T_{b}-T_{a}$ response pattern is apparent. The magnitude and severity of $T_{a}$ ranges, encountered in the field for each season, are probably responsible for the observed statistical differences.

A unique feature of the $T_{b}-T_{a}$ responses shown in Fig. 2 is that the active operating $T_{b}$ in winter is significantly lower than in summer indicating a seasonal acclimatization of $T_{b}$. Seasonal changes in thermolability have been shown for two species of Myotis by

Table 3. Minimum body temperature for flight in certain southwestern bats. $N=$ number of flight trials, not individuals

\begin{tabular}{|c|c|c|c|c|}
\hline Species & $N$ & $\bar{X}$ & 2 S.E. & Range \\
\hline Plecotus townsendii & 51 & 23.48 & 0.51 & $19.60-27.00$ \\
\hline Pipistrellus hesperus ${ }^{\mathrm{a}}$ & 154 & 26.46 & 0.27 & $20.00-30.30$ \\
\hline Myotis thysanodes & 8 & 24.26 & 1.66 & $21.00-26.60$ \\
\hline Lasiurus cinereus & 32 & 25.45 & 0.65 & $21.50 \quad 28.50$ \\
\hline Myotis californicus & 59 & 26.25 & 0.44 & $22.40-29.60$ \\
\hline Antrozous pallidus & 25 & 25.64 & 0.59 & $23.00-28.60$ \\
\hline Myotis volans & 15 & 25.17 & 0.62 & $23.00-27.00$ \\
\hline Myotis evotis & 15 & 25.55 & 0.77 & $23.20-28.50$ \\
\hline Eptesicus fuscus & 8 & 27.58 & 0.96 & $26.30-30.40$ \\
\hline Myotis lucifugus & 11 & 30.31 & 0.43 & $28.60-31.20$ \\
\hline Tadarida brasiliensis & 15 & 31.00 & 0.59 & $31.60-33.60$ \\
\hline
\end{tabular}

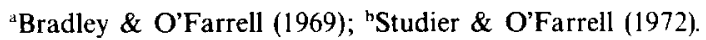




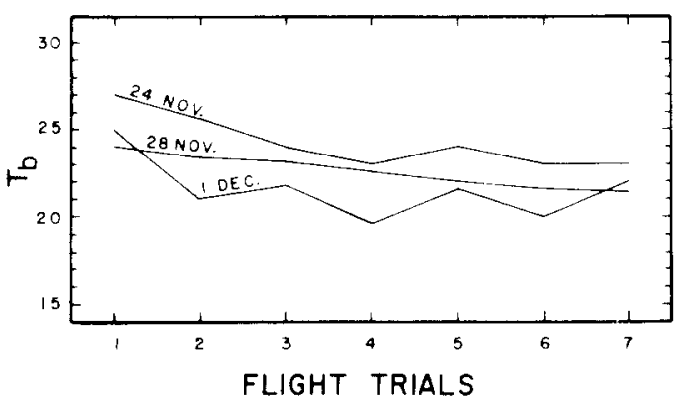

Fig. 3. The minimum body temperature $\left(T_{b}\right)$ required to attain good flight in succeeding flight trials on three different days. All trials are for a single Plecotus townsendii.

Studier \& O'Farrell (1972) under simulated roost conditions. Roberts, Hock \& Smith (1966) have demonstrated significant shifts in $T_{b}$ of Peromyscus maniculatus from summer to winter after exposure to a wide range of $T_{a}$. This shift, however, only encompassed a maximum range of $2^{\circ} \mathrm{C} T_{b}$, and was determined under laboratory conditions. In the present study there was an 8 to $10^{\circ} \mathrm{C} T_{b}$ differential from summer to winter for flying $P$. hesperus. It appears that certain species of bats have the capacity to alter thermoregulatory patterns not only during periods of inactivity but during actual flight. A future examination of changes in total insulation and nerve and muscle response should clarify the mechanisms that are being utilized. It appears, however, that the differences observed between species (Fig. 1) and season (Fig. 2) are mainly due to long term changes such as total insulation. Fur insulation would be expected to change seasonally along with fat levels; Rauch (1975) has also shown seasonal differences in the regional distribution of blood in Eptesicus fuscus. Transition periods of spring and fall show a decided $T_{b}-T_{a}$ response and this is probably a period where short term changes such as in peripheral blood flow (Reeder \& Cowles, 1951; Kluger \& Heath, 1970) are the main regulatory mechanisms. Further studies are warranted to determine hody temperature differentials over the entire body during flight

An examination of laboratory experiments yields insight into the phenomenon of low $T_{b}$ flight. The widespread nature of this phenomenon is apparent (Table 3); only 2 out of 11 desert species tested required a $T_{b}$ of $30^{\circ} \mathrm{C}$ or more to initiate flight. This is in direct conflict with most earlier studies (see review in Studier \& O'Farrell, 1972). The only early study that would indicate the potential of bats to attain flight at low $T_{b}$ is that of Reeder \& Cowles (1951). They report a Plecotus townsendii that was capable of flight at a $T_{b}$ of $24.3^{\circ} \mathrm{C}$. It is of interest that this ability was subsequently ignored by thermoregulation workers until Bradley \& O'Farrell (1969). Also, most studies have dealt with animals which have been maintained in the laboratory for some period of time. Studier \& Wilson (1970) have pointed out that this may account for the lack of thermolability reported in many studies.

A unique aspect of low $T_{b}$ flight is that if a species is capable of low $T_{b}$ flight it can do so regardless of sex or season. Inasmuch as no significant differences were found by sex or season for any of the bats tested in the laboratory. we may assume that the capacity for low $T_{b}$ flight is an inherent physiological mechanism not altered by acclimatization. However, the annual ranges observed in the low $T_{b}$ flight group (Table 3) are broad which may be a function of the degree of stress due to starvation and water deprivation. The data presented in Fig. 3 give further support to the hypothesis that deteriorating body condition allows for activity at lower $T_{b}$ which may function as an energy saving mechanism

Bartholomew (1972) discussed the adaptive nature of heterothermy in relation to temporal patterns of resource availability. Energy utilization was the primary factor discussed although water supply was mentioned in passing. The energetic savings related to low $T_{b}$ flight are obvious and have been discussed previously (Bradley \& O'Farrell, 1969; Studier \& O'Farrell, 1972). However, we do not believe this to be the causative factor.

Winter bat activity is unusual and unexpected in temperate regions due to a lack of food resources (McNab, 1974). It is logical to assume that with the high energetic demands of flight, a bat could not be periodically active without obtaining nourishment. O'Farrell \& Bradley (1970) point out, however, that activity occurred on nights down to $-8^{\circ} \mathrm{C}$ in southern Nevada when insects were not available. This leads us to believe that a factor other than foraging is responsible for observed winter activity.

Most of the desert bats in southern Nevada do not hibernate in stable hibernacula but rather roost mainly in rock fissures. Cross (1965) reports that undisturbed $P$. hesperus usually roost within 6 in. $(15 \mathrm{~cm})$ of the crevice opening. This is sufficient distance to afford adequate protection from $T_{a}$ extremes but shallow enough to permit wide daily fluctuations. In the desert there are many warm winter days. High daytime temperature, coupled with roost position allowing for high incident solar radiation would cause wide daily fluctuations and may physically pull an individual out of hibernation. Kallen (1964) determined that a bat can lose as much body water during arousal from hibernation as it would in 10 days of sustained hibernation. After several days like this the animal would require water or face negative water halance. It has heen previously reported (O'Farrell \& Bradley, 1970) that $P$. hesperus, $M$. californicus and occasionally. $A$. pallidus are continually active throughout the winter months. An examination of stomach contents, light-trapping for insects and observation of bat flight indicate that these bats are primarily flying to obtain water and not for foraging. If fat levels are sufficient and metabolic expenditure reduced even while flying, as reflected by $T_{b}$, then the animals could obtain water periodically without the need for foraging although the possibility of foraging is certainly not precluded under conditions of mild winter evenings.

Acknowledgements - The following colleagues critically read the manuscript and offered many helpful comments and stimulated much discussion: E. H. Studier, F. R. Kay, G. T. Austin and D. O. Straney.

\section{REFERENCES}

Bartholomew G. A. (1972) Aspects of timing and periodicity of heterothermy. (Edited by South F. E., HANNON 
J. P., Willis J. R., Pengelley E. T. \& Alpert N. R.), Hibermation and Hypothermia, Perspectives and Challenges. pp. 663-680. Elsevier, New York.

Bradley W. G. \& O'Farrell M. J. (1969) Temperature relationships of the western pipistrelle (Pipistrellus hesperus). In Physiological Systems in Semi-Arid Environments. (Edited by Hoff C. C. \& Riedesel. M. L.), pp. 85-96. University of New Mexico Press, Albuquerque.

Cross S. P. (1965) Roosting habits of Pipistrellus hesperus. J. Mammal. 46, 270-279.

Henshaw R. E. (1970) Thermoregulation in bats. In About bats. (Edited by Slaughter B. H. \& Walton D. W.), pp. 188-232. Southern Methodist University Press, Dallas, Texas.

Henshaw R. E. \& FolK G. E. JR. (1966) Relation of thermoregulation to seasonally changing microclimate in two species of bats (Myotis lucifugus and $M$. sodalis). Physiol. Zool. 39, 223-236.

KALLEN F. C. (1964) Some aspects of water balance in the hibernating bat. Ann. Acad. Sci. Fenn. Ser. A. IV. 71, 259-267.

Kluger M. J. \& Heath J. E. (1970) Vasomotion in the bat wing: A thermoregulatory response to internal heating. Comp. Biochem. Physiol. 32, 219-226.

LYMAN C. P. (1970) Thermoregulation and metabolism in bats. In Biology of Bats. (Edited by WimsatT William A.), Vol. 1, pp. 301-330. Academic Press, New York.
MCNAB B. K. (1974) The behavior of temperate cave bats in a subtropical environment. Ecology 55, 943-958.

O'Farrell M. J. \& Bradley W. G. (1970) Activity patterns of bats over a desert spring. J. Mammal. 51, 18-26.

Rauch J. C. \& BeatTy D. D. (1975) Comparison of regional blood distribution in Eptesicus fuscus (big brown bat) during torpor (summer), hibernation (winter), and arousal. Can. J. Zool. 53, 207-214.

ReEDeR W. G. \& Cowles R. B. (1951) Aspects of thermoregulation in bats. J. Mammal. 32, 389-403.

Roberts J. C., Hock R. J. \& Smith R. E. (1966) Seasonal metabolic responses of deer mice (Peromyscus) to temperature and altitude. Fed. Proc. Fedn Am. Socs. exp. Biol. 25, 1275-1283.

Scholander P. F., Hock R., Walters V. \& Irving L. (1950) Adaptation to cold in arctic and tropical mammals and birds in relation to body temperature, insulation, and basal metabolic rate. Biol. Bull. 99, 259-271.

Studier E. H. \& O'Farrell M. J. (1972) Biology of $M$ yotis thysanodes and $M$. lucifugus (Chiroptera: Vespertilionidae)-I. Thermoregulation. Comp. Biochem. Physiol. 41A, 567-59.5.

Studier E. H. \& WiLson D. E. (1970) Thermoregulation in some neotropical bats. Comp. Biochem. Physiol. 34 . $251-262$. 